\title{
Comparison of the Characteristics of Transfersomes and Protransfersomes Containing Azelaic Acid
}

\author{
Iskandarsyah*, Aulia Dwi Rahmi, Dwita Medya Pangesti \\ Faculty of Pharmacy, Universitas Indonesia, Depok 16424 West Java, INDONESIA.
}

\begin{abstract}
Objective: Recently developed agent carriers, transfersomes, which are sufficiently deformable to penetrate into or across the skin barrier. Protransfersome is the lyophilization of transfersome by removing the water system with freeze-drying method to improve the protransfersome characterizations, especially entrapment efficiency. The aim of this study was to comparethe characteristics ofazelaic acid transfersomes and protransfersomes. Method: Transfersome was prepared by thin layer hidration method. Protransfersome was prepared by freeze-drying method and trehalose as lyoprotectant. The characterizations that measured were entrapment efficiency, morphological structure, particel size, and zeta potential. Result: The result of Transfersome particel size characterization, pointed out measurement with $89,06 \mathrm{~nm}$. Whereas, after freeze- drying process, Protransfersome A has $735 \mathrm{~nm}$, Protransfersome B has $1218 \mathrm{~nm}$, and Protransfersome $C$ has723,1 nm. There are excalations from 40,98\% of entrapment efficiency after freeze-drying process, Protransfersome A with percentage 45,20\%, Protransfersome B with percentage 45,65\%, and Protransfersome C with percentage 52,90\%. The spheric vesicle morphology of transfersome and protransfersomes is determined by trans-
\end{abstract}

mission electron microscope. Conclusion: Protransfersomes have a better stability in entrapment efficiency by using trehalose or no trehalose with indirect cooling rate within 4 weeks of storage period.

Key words: Azelaic acid, Entrapment afficiency, Freeze-drying, Protransfersome, Transfersome.

Key message: There has been no research yet that compares the stability of azelaic acid transfersome to protransfersome of azelaic acid which uses freeze-drying method with three different steps, which are fast-freezing trehalose step, slow-freezing trehalose step, and slow-freezing step without trehalose.

\section{Correspondence}

Iskandarsyah, Physical Pharmacy Laboratory, Faculty of Pharmacy, Universitas INDONESIA.

Phone: +6281510161488

Email: aya_2803@yahoo.com, icapps2017.farmasiui@gmail.com

DOI: 10.5530/jyp.2018.2s.3

\section{INTRODUCTION}

Azelaic acid mainly used for therapy of Propionibacterium acne and Staphylococcus epidermis, and possesses bacteriostatic properties againts a variety of aerobic microorganism. The use of azelaic acid 15\% gel for topical dermatologic treatment has already been approved by the Food and Drug Administration. ${ }^{1}$ The poor water solubility of azelaic acid results in difficulties in the formulation of this substance for topical application. Transfersomes improve the specificity of topical drug delivery and the overall drug safety. ${ }^{2}$ Transfersome has poor entrapment eficiency. The low amount of EE may be due to the low rigidity that leads to leakage of the lipid bilayer. ${ }^{3}$ The advantage of freeze dried form is a longer stability. Freeze dried form gives a better stability than a conventional transfersome by restraining particel agregation, restraining polimer degradation that forms the vesicle, and restraining leakage of the vesicle. ${ }^{4}$ So protransfersome was made from transfersome by freeze-drying processto improve the protransfersome characterizations, especially entrapment efficiency, by removing water system in the vesicle. The vesicle, a suspension, is transformed into a solid form by this method. ${ }^{4}$

Freeze dried form gives a better characterizations than a conventional transfersome by restraining particel agregation, restraining polimer degradation that forms the vesicle, and restraining leakage of the vesicle. ${ }^{4}$ The aim of this study is to examine effect of freeze-drying towards protransfersomes characterizations, which are compared with characterizations of conventional transfersome. In this research, there are three actions in doing freeze-drying process. Those are direct cooling with trehalose (Protransfersome A), indirect cooling with trehalose (Protransfersome B), and indirect cooling without trehalose (Protransfersome C).

\section{MATERIALS AND METHODS}

\section{Instruments}

Analytical balance (Sartorius), Rotary evaporator (Hahn Shin HS-2005s- N), vacuum evaporator (OSK 6513, Japan), Vortex (As One), Sonicator (Branson 3200), Uv-Vis Spectrophotometer (Shimadzu UV-1800, Japan), pH meter (Eutech Instriument pH 510, Singapore), mini extruder set (Avanti Polar Lipids), polycarbonate membrane $0.45 \mu \mathrm{m}$, and $0.1 \mu \mathrm{m}$ (Whattman), Particel Size Analyzer Zeta Sizer (Malvern Instrument), Freeze Dry(EYELA FD), Ultrasonicator, Transmission Electron Microscope (JEOL JEM 1400), Centrifuge Tube Filter 0,22 $\mu \mathrm{m}$ In $2 \mathrm{ml}$ (Corning), and other glass wares.

\section{Materials}

Azelaic acid (Sigma), Phosphatidylcholine (Phospholipon 90G) (Lipoid, German), Distilled Water (Brataco, Indonesia), Tween 80 (Brataco, Indonesia), Ethanol (Merck, German), Calium Dihydrogen Phosphate Monohydrate (Merck, German), Sodium Hydroxide (Merck, German), Trehalose (PT.Dwipar Loka Ayu, Indonesia), Dichlormethane (Merck, German).

\section{Transfersome production}

Transfersome was prepared by thin layer hydration method. Transfersome formulation of azelaic acid shown in Table 1. Phospholipid was dissolved in dichlormethane, azelaic acid was dissolved in ethanol. Those lipid phase were mixed in a round-bottom flask, and then evaporated by rotary evaporator under temperature $53^{\circ} \mathrm{C}$ and 50-150 rpm, which was applied for $2.5 \mathrm{~h}$. Streamed with $\mathrm{N}_{2}$ gas and closed using wrap plastic, 
Table 1: Formulation of Transfersome.

\begin{tabular}{cc}
\hline Material & Amount \\
\hline Azelaic acid & $24,000 \mathrm{mg}$ \\
Phosphatydilcholine & $24,000 \mathrm{mg}$ \\
Tween 80/Polysorbate 80 & $4,240 \mathrm{mg}$ \\
PBS pH 7,4 & Ad $800 \mathrm{ml}$ \\
\hline
\end{tabular}

stored in low temperature for $24 \mathrm{~h}$, to ensure total removal of solvents. The lipid film was hydrated with phosphate buffer solution (PBS, $\mathrm{pH} 7.4$ ) and tween 80 by rotary evaporator under temperature $40^{\circ} \mathrm{C}$ and $50-150 \mathrm{rpm}$ for $1 \mathrm{~h}$. Ultrasonicated for getting smaller particel size. ${ }^{5}$

\section{Transfersome characterizations Particel size and zeta potential}

Determination of particel size and zeta potential were determined by the dynamic light scattering (DLS) method using Particel Size Analyzer. $1 \mathrm{ml}$ of suspension was dissolved in $9 \mathrm{ml}$ distilled water, then tested in Particel Size Analyzer. ${ }^{6}$

\section{Morphological characterization}

The morphology of vesicle was observed with transmission electron microscope (TEM). Suspension that has dissolved in PBS pH 7,4, was applied to a $\mathrm{Cu}$ grid, coated with carbon film to adsorps sample. Drops uranyl acetate $2 \%$ and then directly examine under the TEM.

\section{Entrapment efficiency}

Entrapment efficiency was performed by indirect method, using centrifugation method which produces supernatan as released drug. The total concentration of active compound measurement was performed by dissolving $1 \mathrm{ml}$ suspension of transfersome with $\mathrm{PBS} \mathrm{pH} 6.8$ in a $10 \mathrm{ml}$ flask. The measurement was performed by using Spectro Uv-Vis at $204 \mathrm{~nm}$.

$$
\mathrm{EE}=\frac{\mathrm{C} \in \text { total }-\mathrm{C} \text { released }}{\mathrm{C} \text { total }} \times 100 \%
$$

With :

$\mathrm{EE}=$ Entrapment efficiency $(\%)$

$\mathrm{C}$ total $=$ Total concentration of the active compound in the transfersome $(\mu \mathrm{g} / \mathrm{ml})$

$\mathrm{C}$ released $=$ Measured concentration of the unentrapped active compound $(\mu \mathrm{g} / \mathrm{ml})$

\section{Freeze-drying}

Transfersome was divided into three portions for freeze-drying process. The first portion was added by $9 \%$ trehalose and cooled directly at low temperature freeze dry ie $-45^{\circ} \mathrm{C}$ (Protransfersome A). The second portion was added by $9 \%$ trehaloseand cooled gradually at room temperature for $3 \mathrm{~h}$, cold temperature for $3 \mathrm{~h}$, freezer temperature $-21^{\circ} \mathrm{C}$ for $15 \mathrm{~h}$, then at freeze drier with temperature $-45^{\circ} \mathrm{C}$ (Protransfersome B). The third portion is done gradually but withouttrehalose addition (Protransfersom C). ${ }^{9}$

\section{Characterizations of protransfersome Particel size and zeta potential}

Vesicle size and zeta potential were determined by dynamic light scattering (DLS) method using Particel Size Analyzer. $50 \mathrm{mg}$ of protransfersome were resuspended in $1 \mathrm{ml}$ of PBS ( $\mathrm{pH}$ 7.4). Suspensions were diluted with $9 \mathrm{ml}$ of distilled water, then analyzed in particel size analyzer. ${ }^{10}$

\section{Morphological characterization}

Vesicle's morphology of protransfersomes were observed by transmission electron microscope (TEM). Protransfersomes were resuspended in PBS ( $\mathrm{pH}$ 7.4) and placed onto a carbon-coated copper grid to absorb sample. A drop of $2 \%$ uranil acetate was added to improve the contrast and then directly examine under the TEM. ${ }^{10}$

\section{Entrapment efficiency}

Entrapment efficiency was determined by indirect method, using centrifuge method which produces supernatant as released drug. $20 \mathrm{mg}$ of protransfersome were resuspended in $10 \mathrm{ml}$ of PBS (pH 7,4). Suspensions was centrifuged to produces supernatant and dissolved with PBS ( $\mathrm{pH}$ 6.8) in a $10 \mathrm{ml}$ flask. The total concentration of active compound measurement was performed by resuspended $20 \mathrm{mg}$ of protransfersome with PBS ( $\mathrm{pH} 7,4)$ and then dissolving suspension of protransfersome with PBS pH 6,8 in a $10 \mathrm{ml}$ flask. The measurement was performed by using Spectro Uv-Vis at $204 \mathrm{~nm}^{8}$

$$
\mathrm{EE}=\frac{\mathrm{C} \text { total }-\mathrm{C} \text { released }}{\mathrm{C} \text { total }} \times 100 \%
$$

with :

$\mathrm{EE}=$ Entrapment efficiency $(\%)$

Ctotal $=$ Total concentration of active subtances in protransfersome $(\mu \mathrm{g} / \mathrm{ml})$ Creleased $=$ Untrapped concentration of active subtances in protransfersome $(\mu \mathrm{g} / \mathrm{ml})$

\section{Stability studies of transfersomes and protransfersomes}

After transfersomes and protransfersomes were done prepared and ready to be characteterized, $100 \mathrm{~mL}$ of transfersomes and $5 \mathrm{gr}$ of each protransfersomes formulation were stored in glass bottle at low temperature $\left(4 \pm 2^{\circ} \mathrm{C}\right)$ and room temperature $\left(28 \pm 2^{\circ} \mathrm{C}\right)$ for a period of 4 weeks. The percentage entrapment of the drug and vesicle size were determined after 14 and 28 days.

\section{RESULTS}

\section{Particel Size and Zeta Potential}

The average size of the azelaic acid transfersome particels was $89.06 \mathrm{~nm}$, with zeta potential of $-0.558 \mathrm{mV}$ and the polydispersity index (PDI) of 0.292. Transfersome particel size has shown good results of less than 200 $\mathrm{nm}$ and a monodisperse suspension based on a PDI value less than $0.6 .^{11}$ While the zeta potential value shown by transfersome was outside the criterion that is $+/-30 \mathrm{mV}$. The zeta potential obtained at only -0.552 indicates a large particel aggregation in the suspension. This gain can be due to the use of tween 80 which generally provides a positive zeta potential. ${ }^{12}$

Protransfersome that has done the freeze-drying process shows the enlargement of particel size and PDI. Protransfersome A has the particel size of $735 \mathrm{~nm}$, PDI 0.580 , and zeta potential $-5.03 \mathrm{mV}$. Protransfersom $B$ has a particel size of $1218 \mathrm{~nm}$, PDI 0.901 , and zeta potential $-8.67 \mathrm{mV}$. While Protransfersom C has particel size of $723.1 \mathrm{~nm}$, PDI 0.849 , and zeta potential $-3 \mathrm{mV}$.

\section{Morphological Characterization}

The results of the transmission electron microscope, azelaic acid transfersome have a spherical morphology with multilamelar transfersome type. This is shown in Figure 1.

Freeze-drying forms protransfersome, showing spherical morphology as before based on observations with transmission electron microscopy. This is shown in Figure 2, 3 and 4. 


\section{The Entrapment Efficiency}

The entrapment efficiency of transfersome azelaic acid obtained was $40,98 \%$ an average of three experiments.After freeze-drying process, the entrapment efficiency of each protransfersom was increased. The average of entrapment efficiency of protransfersome A, B, and C were $45.20 \%$; 45.65\%; And 52.90\% respectively.

\section{Stability Studies}

Transfersome and Protransfersomes stability was evaluated for 4 weeks with once two weeks testing. The evaluated characteristics are entrapment efficiency and particel size. Particel size stability in room temperature is shown in Figure 5.

In this storage condition, with room temperature, the particel size of transfersome was stable. The particel size of Protransfersome A was increasing during storage time.. Meanwhile, Protransfersome B and C
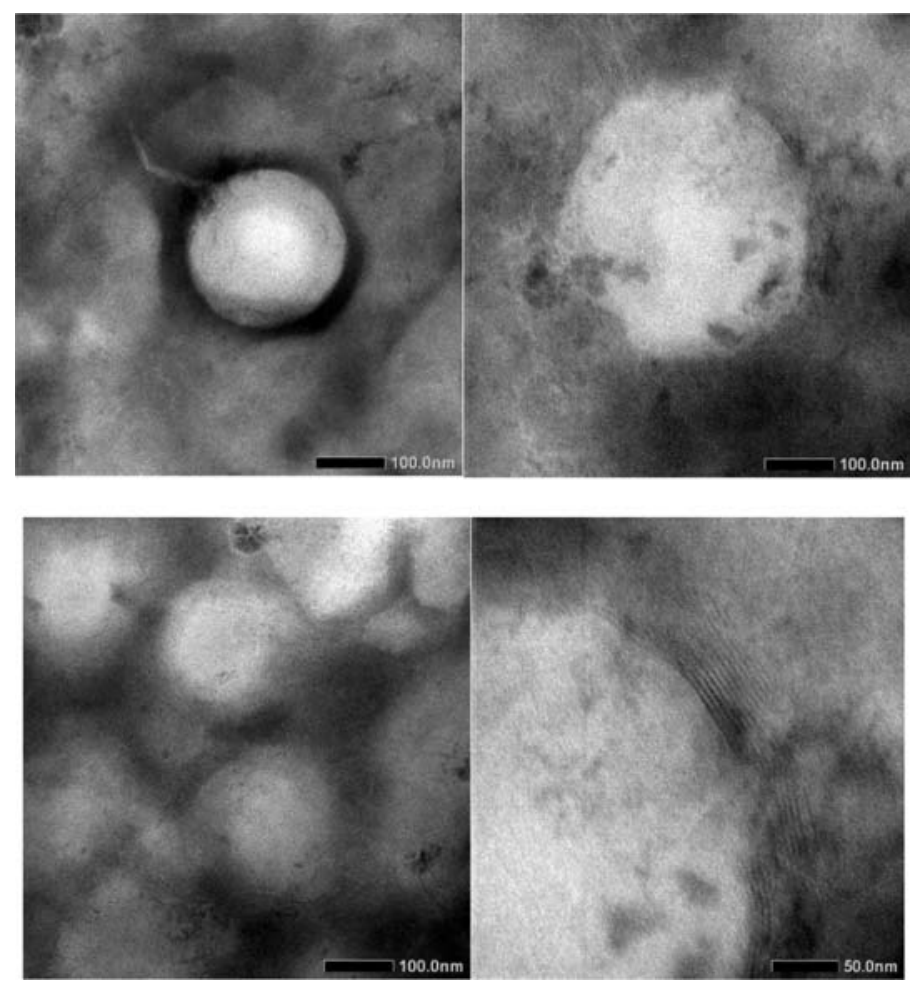

Figure 1: The morphology of transfersome by transmission electron microscope.

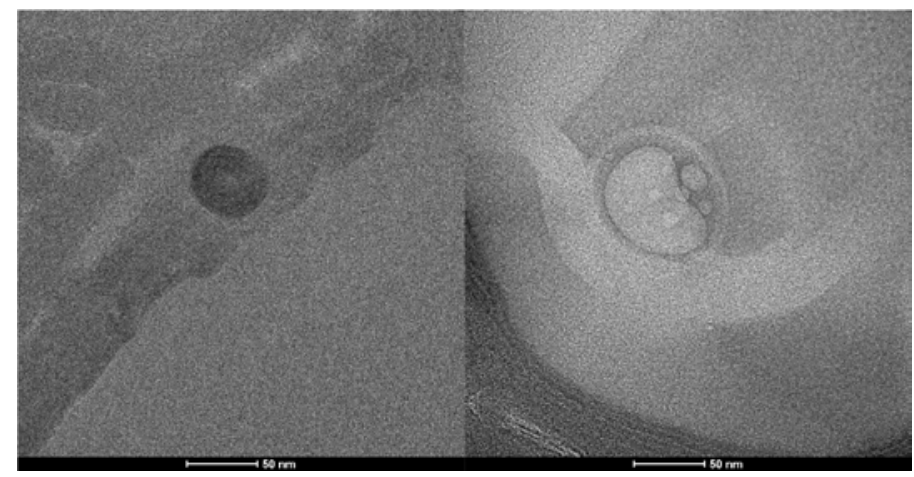

Figure 2: The morphology of protransfersome A by transmission electron microscope.

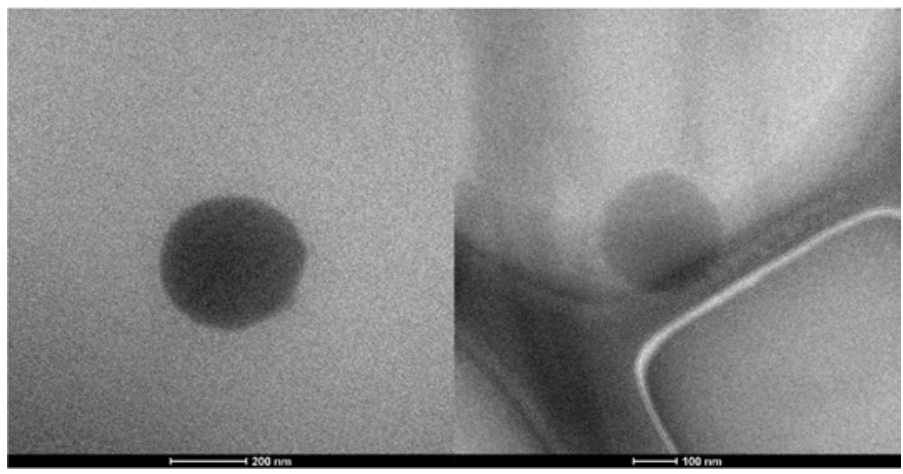

Figure 3: The morphology of protransfersome B by transmission electron microscope.

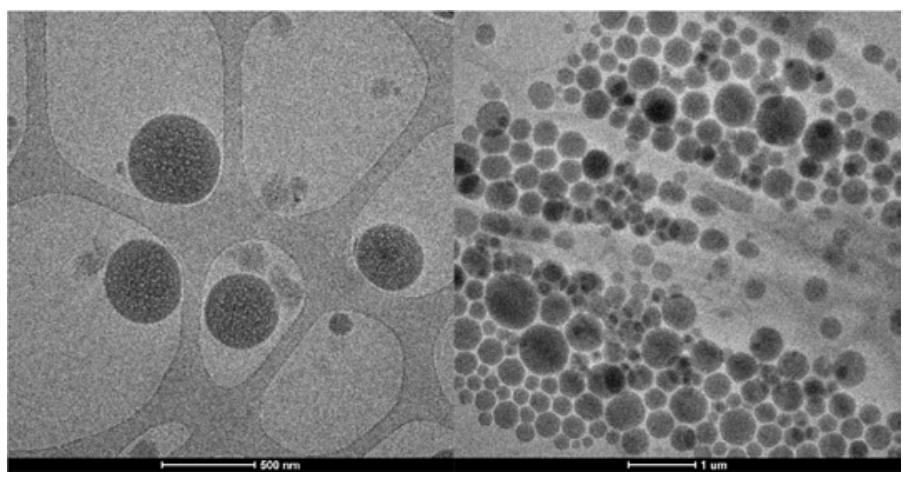

Figure 4: The morphology of protransfersome $\mathrm{C}$ by transmission electron microscope.

Particle Size Stability in Room Temperature

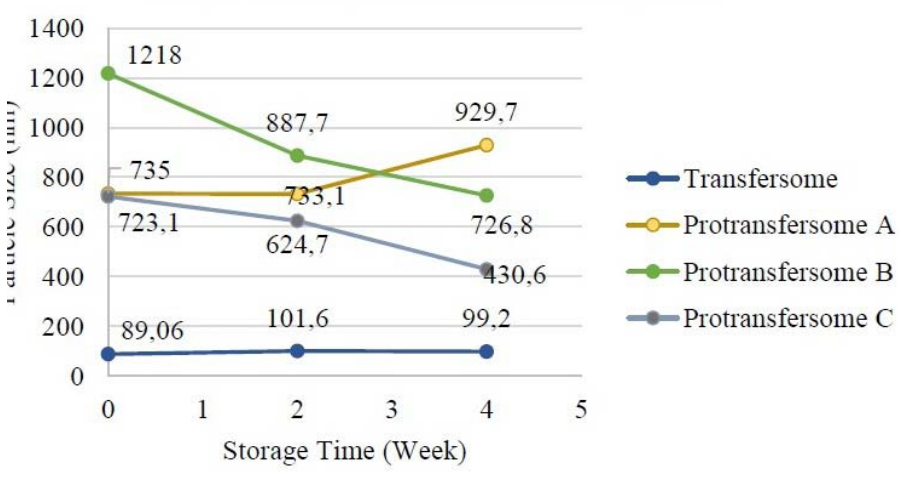

Figure 5: Particel Size Stability in Room Temperature.

Particle Size Stability in Low Temperature $4^{\circ} \mathrm{C}$

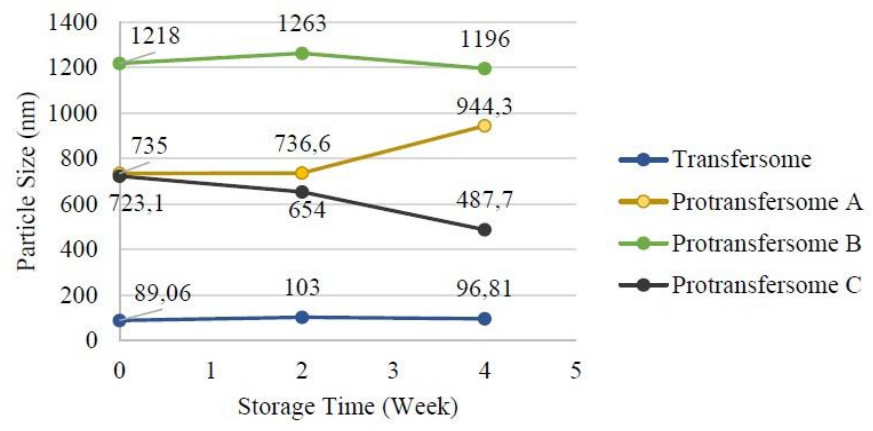

Figure 6: Particel Size Stability in Low Temperature $4^{\circ} \mathrm{C}$ 


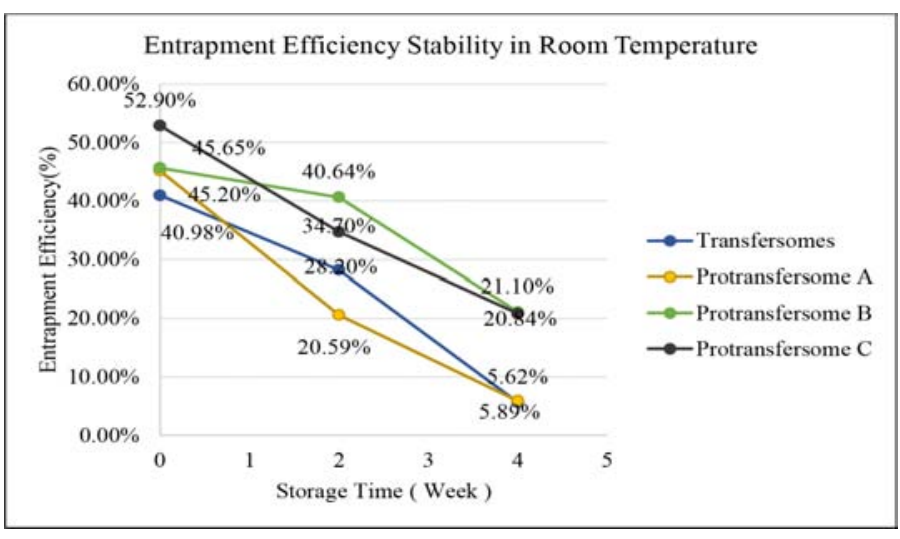

Figure 7: Entrapment Efficiency Stability in Low Temperature $4^{\circ} \mathrm{C}$.

\section{Entrapment Efficiency Stability in Low Temperature} $4^{\circ} \mathrm{C}$

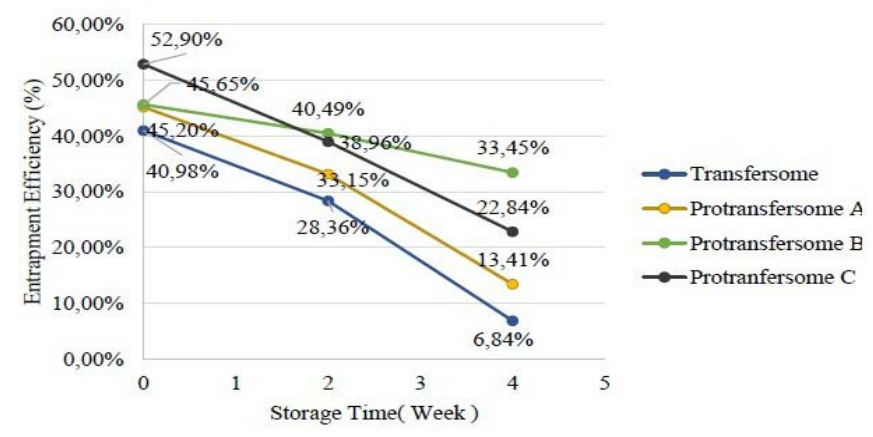

Figure 8: Entrapment efficiency stability in low temperature.

got particel size reduction during storage time. Particel size stability in low temperature $4^{\circ} \mathrm{C}$ is shown in Figure 6 .

In this storage condition, in low temperature, the particel size of transfersome and protransfersome B was stable. In other hand, Protransfersome A got a bigger particel size after 4 weeks,. Protransfersome $C$ got a smaller particel size after two and four weeks testing. Entrapment efficiency stability in room temperature is shown in Figure 7.

Storage condition with room temperature, all vesicles, transfersome and protransfersomes, have got entrapment efficiency reduction since 2 weeks of storage. The smallest of entrapment efficiency reduction was provided by Protransfersome B and Protransfersome C. Protransfersome $\mathrm{C}$ has a slightly bigger reduction in entrapment efficiency than protransferome B. Entrapment effiency stability in low temperature $4^{\circ} \mathrm{C}$ is shown in Figure 8.

Storage condition inlow temperature, the reduction of entrapment efficiency was shown by all vesicles. But, Protransfersome B and Protransfersome $\mathrm{C}$ provide a better stability with the smallest reduction than Protransfersome A and Transfersome.

\section{DISCUSSION}

The enlargement of particel size after freeze-drying process can be caused by the aggregation of particels that make its size increases during lyophilization process and poor of zeta potential. ${ }^{13-14}$ The small vesicle, such as 50-300 $\mathrm{nm}$, will usually get bigger in size after the freeze-drying method. Meanwhile, the bigger vesicle, such as $20 \mu \mathrm{m}$, will usually get smaller after the freeze-drying method. ${ }^{15}$ In addition, the use of trehalose as a lyoprotectant also causes the formation of layers outside the vesicle so that the size larger. The use of tween 80 as the edge activator or surfactant can also affects the particel size. Particel size increases along surfactant posessing lower hydrophile-lipophile balance (HLB). ${ }^{16}$ PDI also increases along with increasing particel size. The zeta potential after the freeze-drying process shows better results, but still does not meet the criteria of $+/-30 \mathrm{mV}$. However, out of these protransfersomes, Protransfersome B is the stablest or the least agregated between Protransfersome A dan protransfersome C. Based on observations, the spherical morphology before freeze-drying can be mantained after freeze-drying process.

The entrapment efficiency of transfersome dan protransfersome azelaic acid are still far away from $100 \%$ due to the concentration of active substances used only $3 \%$. Basically transfersome manufacture includes the principle of solving and merging. The more concentration of active substance used, the higher the chance of the active substances to be entrapped. ${ }^{17}$ In addition, the use of soybeans phospholipids can also be a factor of the poor entrapment efficiency. Generally, the use of phospholipid from eggs will provide greater efficiency than soybeans. ${ }^{18}$ However, because the azelaic acid is used for the tropical use, the phospholipid from an egg is usually avoided because of its smell. The use of trehalosa in the freeze-drying method is to protect vesicles from the freezing stress and the drying stress. ${ }^{4}$ Lyophilization of nanovesicles can causes instability toward particel agregation, physical properties, $\mathrm{pH}$, and drug loading. The absence of lyoprotectant during freeze-drying can also affect the entrapment efficiency. ${ }^{19}$ Trehalose has low higroscopisity and internal hydrogen bond which make it flexible to create hydrogen bond with nanovesicle. ${ }^{4}$ After freeze-drying process, the entrapment efficiency of each protransfersom was increased. The increased of entrapment efficiency was due to the aggregation of particel so that the size becomes large and the more active substances were entrapped. ${ }^{20}$ Moreover, the rigidity of lipid membrant increases, so the permeability from the lipid membrant decreases, and the leak of the drug from the transfersome membrant can be prevented.

In room temperature, the particel size of transfersome was stable. The particel size of Protransfersome A was increasing during storage time. The reason is agregation which leads to make a bigger particel. In low temperature, the particel size of transfersome and protransfersome B was stable. In other hand, Protransfersome A got a bigger particel size after 4 weeks, because of agregation. Protransfersome $\mathrm{C}$ got a smaller particel size after two and four weeks testing due to leakage of lipid bilayer membrane. This is shown that trehalose did a good job by protecting protransfersome during 4 weeks of storage time.

Storage condition in room temperature, all vesicles, transfersome and protransfersomes, have got entrapment efficiency reduction since 2 weeks of storage. The reason is leakage which makes discharging of drug from the vesicle and become free dugs in the dispersion medium. One of the reason why leakage was happened is degradation of lipid bilayer along with the temperatures increased., ${ }^{3,17}$ Moreover, chemical degradation reactions can affect the stability of phospholipid bilayers, such as hydrolysis the ester bonds linking the fatty acids to glycerol backbone. The oxidation and hydrolysis of lipids may lead to an appearance of short chain lipids and then soluble derivatives will form in the membrane. ${ }^{21}$ The smallest of entrapment efficiency reduction was provided by Protransfersome B and Protransfersome C. This is proven that indirect cooling rate can gives a better stability toward the vesicle. Protransfersome $\mathrm{C}$ has a slightly bigger reduction in entrapment efficiency than protransferome B. This is proven that trehalose protected membrane integrity and in preventing leakage. ${ }^{22-23}$ Storage condition with low temperature, the reduction of entrapment efficiency was shown by all vesicles. But, Protransfersome B and Protransfersome C provide a better stability with the smallest reduction than Protransfersome A and Transfersome.This is because Protransfersome B and Protransfersome C in the 
freeze-drying process are slowly frozen that make water difusion take slow in the freeze-drying process. So, the osmotic pressure decreases and the droplet leak in the vesicle can be prevented. ${ }^{24}$

\section{CONCLUSION}

Freeze-drying provides a better characteristic of protransfersomes especially the entrapment efficiency, and a better stability of the entrapment efficiency in low temperature during storage period by using trehalose or without trehalose with indirect cooling rate. The spherical morphology before freeze-drying can be mantained after freeze-drying process.

\section{ACKNOWLEDGEMENT}

The authors gratefully acknowledge the support of this research by Malvern Instrument Jakarta, Nanotechnology Laboratory Bogor, LIPI Bogor, and PITTA Universitas Indonesia.

\section{CONFLICT OF INTEREST}

This research was granted by PITTA Universitas Indonesia.

\section{SUMMARY}

- Transfersome shown better stability of particel size in room temperature than other vesicles.

- The best stability of particel size in low temperature $4^{\circ} \mathrm{C}$ was shown by Transfersome and Protransfersome B.

- $\quad$ Storage condition in room and low temperature $4^{\circ} \mathrm{C}$, all vesicles, Transfersome and Protrasnfersomes, have got entrapment efficiency reduction. The smallest of entrapment effiency reduction was provided by Protransfersomes B and Protransfersome C.

\section{REFERENCES}

1. Garelnabi M, Litvinov D, Parthasarathy S. Evaluation of a gaschromatography method for azelaic acid determination in selected biological samples. N Am J Med Sci. 2010;2(9):397-402

2. Manosroi J, Apriyani MG, Foe K, Manosroi A. Enhancement of the release of azelaic acid through the synthetic membranes by inclusion complex formation with hydroxypropyl- $\beta$-cyclodextrin. Int J Pharm. 2005;293(1-2):235-40.

3. Shivani SS, Srujan MK. Novel vesicular carrier for enhanced transdermal delivery of tramadol hydrochloride transfersomal gel. J Pharm Biomed Sci. 2016; 6(3):139-44

4. Abdelwahed W, Degobert G, Stainmesse S, Fessi H. Freeze-drying of nanoparticels: Formulation, process and storage considerations. Adv Drug Deliv Rev. 2006;58(15):1688-713
5. Laxmi MV, Zafaruddin M, Kuchana V. Design and characterization of transferosomal gel of repaglinide. Int Res J Pharm. 2015;6(1):38-42.

6. Duangjit S, Opanasopit P, Rojanarata T, Ngawhirunpat T. Evaluation of meloxicamloaded cationic transfersomes as transdermal drug delivery carriers. AAPS Pharm Sci Tech. 2013;14(1):133-40.

7. Chaudhary $H$, Kohli $Z$, Kumar V. A novel nano-carrier transdermal gel against inflammation. Int Res J Pharm. 2014;465(1-2):175-86.

8. Tavano L, Alfano P, Muzzalupo R, De Cindio B. Niosomes vs microemulsions: New carriers for topical delivery of Capsaicin. Colloids Surf B: Biointerfaces. $2011 ; 87(2): 333-9$

9. Guan P, LuY, Qi J, WuW. Readily restoring freeze-dried probilosomes as potential nanocarriers for enhancing oral delivery of cyclosporine A. Colloids Surf B: Biointerfaces. 2016;144,143-51.

10. Gupta $\vee$, Trivedi P. Enhancement of storage stability of cisplatin-loaded protransfersome topical drug delivery system by surface modification with block copolymer and gelling agent. J Drug Deliv Sci Technol. 2012;22(4):361-6.

11. Malvern ZetaSizer. Malvern Zetasizer SZ user manual. 2013:2-15.

12. Al Shuwaili AH, Rasool BK, Abdulrasool AA. Optimization of elastic transfersomes formulations for transdermal delivery of pentoxifylline. Eur $\mathrm{J}$ Pharm Biopharm. 2016;102:101-14.

13. Bejrapha P, Surassmo S, Choi MJ, Nakagawa K, Min SG. Studies on the role of gelatin as a cryo- and lyo-protectant in the stability of capsicum oleoresin nanocapsules in gelatin matrix. J Food Eng. 2011;105(2):320-31.

14. Van Winden EC, Crommelin DJ. Long term stability of freeze-dried, lyoprotected doxorubicin liposomes. Eur J Pharm Biopharm. 1997;43(3):307-295.

15. Chen $C$, Han D, Zhang $Y$, Yuan $Y$, Tang $X$. The freeze-thawed and freeze-dried stability of cytarabine-encapsulated multivesicular liposomes. Int J Pharm. 2010;387(1-2):147-53.

16. Nimisha, Rizvi DA, Fatima Z, Neema, Kaur CD. Antipsoriatic and anti-inflammatory studies of Berberis aristata extract loaded nanovesicular gels. Phcog Mag. 2017;13(S3):587-94.

17. Sugiyati R, Iskandarsyah, Djajadisastra J. Formulasi dan uji penetrasi in vitro sediaan gel transfersom mengandung kofein sebagai antiselulit. Jurnal IImu Kefarmasian Indonesia, 2017;13(2):131-6.

18. Sharma V, Yusuf M, Pathak K. Nanovesicles for transdermal delivery of felodipine: Development, characterization, and pharmacokinetics. Int J Pharm Investig. 2014;4(3):119-30.

19. ChinembiriTN, Gerber M, Du Plessis LH, Du Preez JL, Hamman JH, Du Plessis $J$. Topical delivery of Withania somnifera crude extracts in niosomes and solid lipid nanoparticels. Phcog Mag. 2017;13(S3):663-71.

20. El-Nesr OH, Yahiya SA, El-Gazayerly ON. Effect of formulation design and freeze-drying on properties of fluconazole multilamellar liposomes. Saudi Pharm J. 2010;18(4);217-24.

21. Yadav AV, MS Murthy, Shete AS, Sakhare S. Stability Aspects of Liposomes. Ind J Pharm Edu Res. 2011;45(4):413.

22. Crowe LM, Womersley C, CroweJH, Reid D, Appel L, Rudolph A. Prevention of fusion and leakage in freeze-dried liposomes by carbohydrates. Biochim Biophys Acta Biomembranes. 1986;861:131-40.

23. Madden TD, Bally MB, Hope MJ, Cullis PR, Schieren HP, Janoff AS. Protection of large unilameilar vesicles by trehalose during dehydration : retention of vesicle contents. 1985;817(1):67-74.

24. Morais, Andreza Rochelle do Vale, et al. Freeze Drying of Emulsified Systems : A Review. Int J Pharm. 2016;503(1-2):102-14.

Article History: Submission Date : 21-12-2017 ; Revised Date : 28-01-2018; Acceptance Date : 12-03-2018.

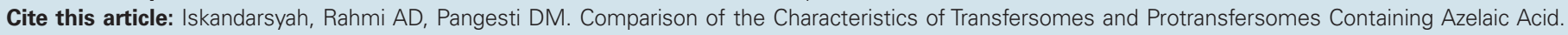
J Young Pharm. 2018;10(2)Suppl:s11-s15. 